\title{
WILDERNESS IMAGES
}

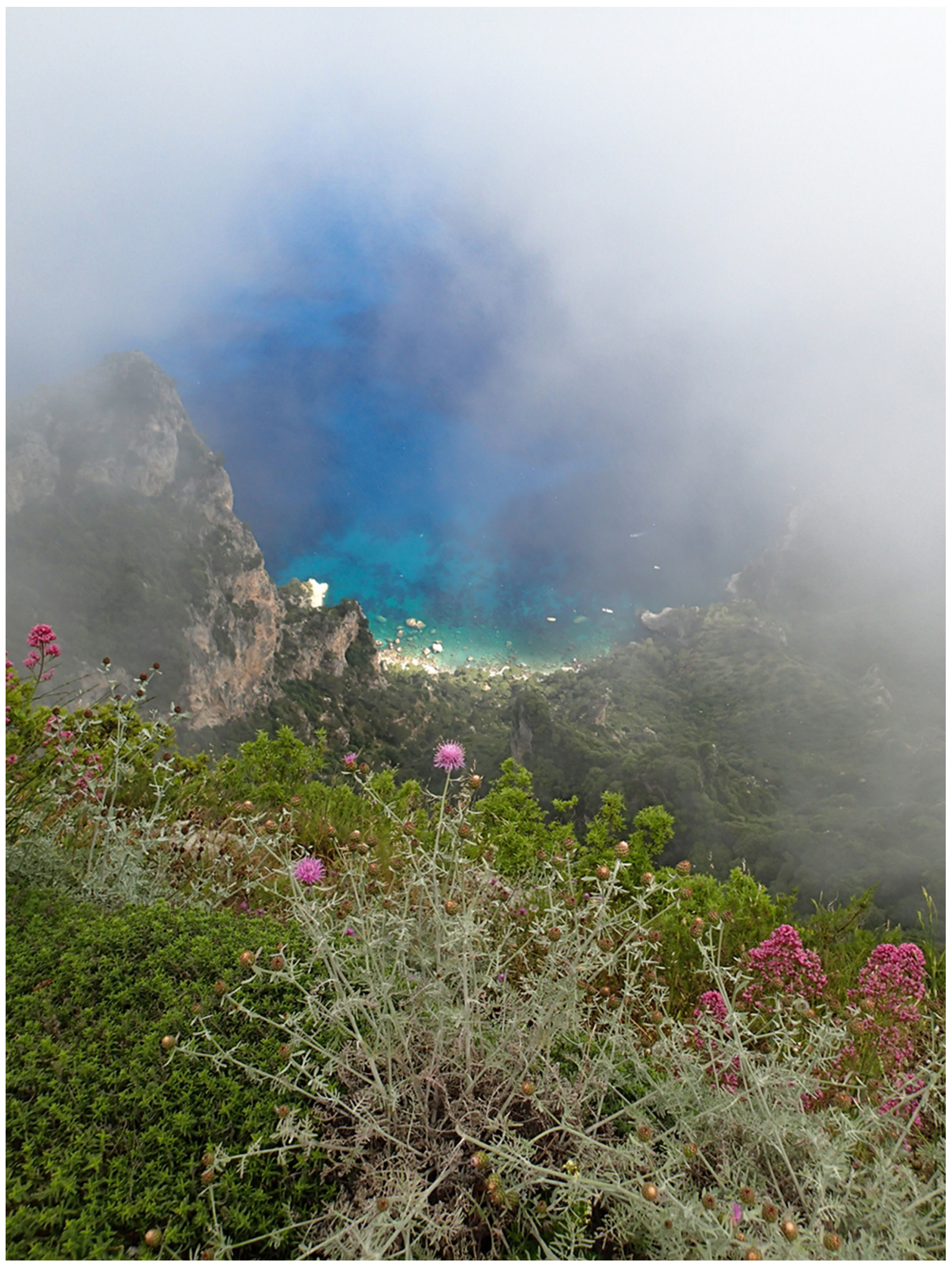

Overlooking. Monte Solaro on the island of Capri in Campania, Italy. Photograph by Jon Conard, DO. 